\title{
Altered Gene Expression by Low-Dose Arsenic Exposure in Humans and Cultured Cardiomyocytes: Assessment by Real-Time PCR Arrays
}

\author{
Jinyao Mo ${ }^{1}$, Yajuan Xia ${ }^{2}$, Timothy J. Wade ${ }^{3, *}$, David M. DeMarini ${ }^{3}$, Mercy Davidson ${ }^{4}$ \\ and Judy Mumford ${ }^{3}$
}

1 Center for Environmental Medicine, Asthma and Lung Biology, University of North Carolina, Chapel Hill, NC 27599, USA; E-Mail: jin_mo@med.unc.edu

2 Inner Mongolia Center for Endemic Disease Control and Research, Huhhot 010031, Inner Mongolia, China; E-Mail: yajxia@126.com

3 National Health and Environmental Effects Research Laboratory, U.S. Environmental Protection Agency, Research Triangle Park, NC 27711, USA; E-Mails: demarini.david@epa.gov (D.M.D.); jmumford5@gmail.com (J.M.)

4 Department of Radiation Oncology, Columbia University, New York, NY 10032, USA;

E-Mail: mmd2@columbia.edu

* Author to whom correspondence should be addressed; E-Mail: wade.tim@epa.gov; Tel.: +1-919-966-8900; Fax: +1-919-966-0655.

Received: 12 April 2011; in revised form: 21 May 2011 / Accepted: 27 May 2011 /

Published: 8 June 2011

\begin{abstract}
Chronic arsenic exposure results in higher risk of skin, lung, and bladder cancer, as well as cardiovascular disease and diabetes. The purpose of this study was to investigate the effects on expression of selected genes in the blood lymphocytes from 159 people exposed chronically to arsenic in their drinking water using a novel RT-PCR TaqMan low-density array (TLDA). We found that expression of tumor necrosis factor- $\alpha(T N F-\alpha)$, which activates both inflammation and NF- $\kappa \mathrm{B}$-dependent survival pathways, was strongly associated with water and urinary arsenic levels. Expression of KCNA5, which encodes a potassium ion channel protein, was positively associated with water and toe nail arsenic levels. Expression of 2 and 11 genes were positively associated with nail and urinary arsenic, respectively. Because arsenic exposure has been reported to be associated with long QT intervals and vascular disease in humans, we also used this TLDA for analysis of gene expression in human cardiomyocytes exposed to arsenic in vitro. Expression of the
\end{abstract}


ion-channel genes $C A C N A 1, K C N H 2, K C N Q 1$ and $K C N E 1$ were down-regulated by $1-\mu \mathrm{M}$ arsenic. Alteration of some common pathways, including those involved in oxidative stress, inflammatory signaling, and ion-channel function, may underlay the seemingly disparate array of arsenic-associated diseases, such as cancer, cardiovascular disease, and diabetes.

Keywords: arsenic; drinking water; low-density array; real-time PCR; cardiomycocytes

\section{Introduction}

Extensive epidemiological studies have demonstrated that environmental exposure to arsenic causes cancer of the skin, lung, and bladder [1-3] and is also a co-carcinogen in combination with UV light for skin cancer [4]. In addition, exposure to arsenic either chronically through the drinking water [5] or acutely through medical therapy for acute promyelocytic leukemia or poisoning [6,7] is associated with cardiovascular abnormalities [8,9]. This is frequently manifest as a prolongation of the QT (time between initial deflection of QRS complex to the end of T wave) interval as measured on an electrocardiogram, resulting in life-threatening malignant ventricular arrhythmias [7].

Mechanistic studies indicate that arsenic enhances inflammation of vascular tissues, activates oxidative signaling, disrupts lipid metabolism, and increases lipid oxidation [8]. These effects can produce endothelial cell dysfunction directly to the vascular cells and indirectly through the liver. In addition, the epigenetic changes induced by arsenic in the liver appear to produce a chronic state of stress and inflammation, resulting in not only liver disease but also systemic vascular disease [8]. In particular, arsenic exposure increases the risk of prolonged QT interval duration, which is associated with atherosclerosis $[10,11]$. No studies have implicated a role for arsenic on cardiomyocytes per se; however, to our knowledge, no in vitro exposures of such cells to arsenic have been performed.

To understand these diverse effects of arsenic, toxicogenomic analyses involving cDNA microarray have been used to identify alterations in global gene expression and pathways in cells exposed to arsenic in vitro as well as in animals and humans exposed to arsenic [12-16]. The aberrantly expressed genes identified in these studies include those coding for heat shock proteins, DNA damage response, antioxidant activity, inflammation signaling, cell-cycle regulation, and apoptosis [16].

Although global gene expression studies have provided considerable insights into the toxicity pathways affected by arsenic, real-time PCR (RT-PCR) has been used to confirm the arsenic-associated altered gene expression of only a few genes in these studies. The development of a novel qRT-PCR-based technique called Taqman Low-Density Array (TLDA) allows for the simultaneous testing of 48 or 96 genes in a micro-fluidic card format in which the user can specify the genes to be analyzed [17]. This technology has been shown to be a sensitive and reproducible system for analyzing gene expression [18], and it could be of value in confirming the ability of arsenic to alter the expression of genes identified initially by cDNA microarray.

To explore this possibility, and especially to assess some of the toxicogenomic effects of arsenic associated with cardiovascular abnormalities, we used a TLDA to evaluate gene expression in 48 genes in RNA isolated from (a) blood of 159 subjects exposed chronically to arsenic as well as (b) human cardiomyocytes exposed in vitro to arsenic. The 48 genes (Table 1) were selected based on the 
previous cDNA microarray studies described above and fell into 10 functional groups: endogenous control, Nrf2 pathway, heat shock protein, apoptosis, inflammation, NF- $\kappa \mathrm{B}$ pathway, cell proliferation DNA methylation, DNA repair, and ion channel.

Table 1. Genes analyzed by TLDA.

\begin{tabular}{|c|c|c|}
\hline Gene symbol and assay ID & Functional group & Gene description \\
\hline ACTB-Hs00242273_m1 & Endogenous control & beta actin \\
\hline 18S-Hs99999901_s1 & & 18S Ribosomal RNA \\
\hline HMOX1-Hs00157965_m1 & Nrf2 pathway & \\
\hline KEAP1-Hs00202227_m1 & & kelch-like ECH-associated protein 1 \\
\hline \multicolumn{3}{|l|}{ MAF-Hs00193519_m1 } \\
\hline \multicolumn{3}{|l|}{ MT1A-Hs00831826_s1 } \\
\hline \multicolumn{3}{|l|}{ NQO1-Hs00168547_m1 } \\
\hline HSPA1A-Hs00359163_s1 & Heat shock protein & \\
\hline \multicolumn{3}{|l|}{ HSP90AA1-Hs00743767_sH } \\
\hline BAX-Hs00180269_m1 & Apoptosis & \\
\hline \multicolumn{3}{|l|}{ BCL2-Hs00153350_m1 } \\
\hline IL1B-Hs00174097_m1 & Inflammation & \\
\hline \multicolumn{3}{|l|}{ IL2-Hs00174114_m1 } \\
\hline \multicolumn{3}{|l|}{ IL6-Hs00174131_m1 } \\
\hline \multicolumn{3}{|l|}{ TNF-Hs00174128_m1 } \\
\hline CHUK-Hs00175141_m1 & $\mathrm{NF}-\kappa \mathrm{B}$ pathway & \\
\hline NFE2L2-Hs00232352_m1 & & nuclear factor (erythroid-derived 2)-like 2 \\
\hline NFKB1-Hs00231653_m1 & & nuclear factor in B-cells 1 (p105) \\
\hline NFKB2-Hs00174517_m1 & & nuclear factor in B-cells 2 (p49/p100) \\
\hline \multicolumn{3}{|l|}{ RELB-Hs00232399_m1 } \\
\hline \multicolumn{3}{|l|}{ RELA-Hs00153294_m1 } \\
\hline CDKN1A-Hs00355782_m1 & Cell proliferation & \\
\hline \multicolumn{3}{|l|}{ CCND1-Hs00277039_m1 } \\
\hline \multicolumn{3}{|l|}{ ESR1-Hs00174860_m1 } \\
\hline \multicolumn{3}{|l|}{ FOS-Hs00170630_m1 } \\
\hline \multicolumn{3}{|l|}{ JUN-Hs99999141_s1 } \\
\hline \multicolumn{3}{|l|}{ MYC-Hs00153408_m1 } \\
\hline \multicolumn{3}{|l|}{ MSH2-Hs00179887_m1 } \\
\hline \multicolumn{3}{|l|}{ NRAS-Hs00180035_m1 } \\
\hline \multicolumn{3}{|l|}{ TERT-Hs00162669_m1 } \\
\hline DNMT1-Hs00154749_m1 & DNA methylation & DNA (cytosine-5-)-methyltransferase 1 \\
\hline \multicolumn{3}{|l|}{ DNMT3A-Hs00173377_m1 } \\
\hline ERCC1-Hs00157415_m1 & DNA repair & \\
\hline \multicolumn{3}{|l|}{ MGMT-Hs00172470_m1 } \\
\hline \multicolumn{3}{|l|}{ NTHL1-Hs00267385_m1 } \\
\hline \multicolumn{3}{|l|}{ OGG1-Hs00213454_m1 } \\
\hline POLB-Hs00160263_m1 & & \\
\hline
\end{tabular}


Table 1. Cont.

\begin{tabular}{lll}
\hline Gene symbol and assay ID & Functional group & Gene description \\
\hline $\begin{array}{l}\text { DNMT1-Hs00154749_m1 } \\
\text { RAD50-Hs00194871_m1 }\end{array}$ & DNA methylation & DNA (cytosine-5-)-methyltransferase 1 \\
TP53-Hs00153349_m1 & & \\
\hline CACNA1C-Hs00167681_m1 & Ion channel & calcium channel, voltage-dependent, L type, alpha 1C subunit \\
SCN5A-Hs00165693_m1 & & $\begin{array}{l}\text { sodium channel, voltage-gated, type V, alpha (long QT } \\
\text { syndrome 3) } \\
\text { KCNJ2-Hs00265315_m1 }\end{array}$ \\
KCNA5-Hs00266898_s1 & potassium inwardly-rectifying channel, subfamily J, member 2 \\
& potassium voltage-gated channel, shaker-related subfamily, \\
KCND3-Hs00542597_m1 & member 5 \\
& potassium voltage-gated channel, Shal-related subfamily, \\
& member 3 \\
KCNE1-Hs00264799_s1 & potassium voltage-gated channel, Isk-related family, member 1 \\
KCNQ1-Hs00165003_m1 & potassium voltage-gated channel, KQT-like subfamily, \\
& member 1 \\
KCNH2-Hs00165120_m1 & potassium voltage-gated channel, subfamily H (eag-related), \\
& member 2 \\
KCNE2-Hs00270822_s1 & potassium voltage-gated channel, Isk-related family, member 2 \\
\hline
\end{tabular}

This array was used to evaluate gene expression in an arsenic-treated human cardiomyocyte cell line (AC16) and in blood from subjects living in Bayingorman (Ba Men) Inner Mongolia, China. This population has been exposed to a wide range of arsenic levels (from non-detectable to $1.8 \mathrm{mg} / \mathrm{L}$ ), mainly via drinking water from contaminated artesian wells for more than 20 years [19]. Seafood consumption is not common in this population, and arsenic-containing pesticides have not been used in Ba Men [20]. In Ba Men, more than 300,000 people have been chronically exposed to arsenic, especially in three counties: Hangjin Hou, Lin He and $\mathrm{Wu}$ Yuan. Arsenic-associated health effects in this population include cancer, dermal, neurological, cardiovascular, and peripheral vascular diseases $[9,19]$. More than 80 percent of the families owned individual wells, making it possible to assess the arsenic exposure at the individual level.

We assessed arsenic levels in the water from each household well and also in toenails and urine of each subject. This exposure assessment permitted us to associate gene expression in the blood of the subjects to each measure of exposure. In addition, we compared the results in the blood to those determined in cardiomyocytes exposed to arsenic in vitro. This provided an opportunity to see if arsenic might have a direct effect on such cells, resulting in changes in gene expression found in blood and/or consistent with the cardiovascular myopathies associated with arsenic exposure.

\section{Experimental Section}

\subsection{Study Subjects}

The study subjects included a total of 159 non-smoking Ba Men residents from the sub-villages of Wulan, Jianshe, Fengchan, and Xinyao located in Sha Hai Village, Hangjn Hou County and the sub-villages of Miaohao and Xigelian located in Sheng Feng Village, Wu Yuan County. 
Questionnaires were administered to all participants to obtain demographic information, arsenic exposure, diet, smoking, occupation, pesticide use, and medical information. This study was conducted according to the recommendations of the World Medical Association Declaration of Helsinki [21] for international health research. All subjects gave written informed consent to participate in this study. The research protocol met the requirements for protection of human subject certification by the U.S. Environmental Protection Agency.

\subsection{Water Collection and Analysis}

Samples of drinking water from wells were collected from all subjects' homes in acid-washed tubes, transported to the U.S. on blue ice, and analyzed for total arsenic using inductively coupled plasma mass spectrometry (ICPMS) as described previously [22]. The detection limit by ICPMS was $0.1 \mu \mathrm{g}$ of $\mathrm{As}^{\mathrm{III}} / \mathrm{L}$.

\subsection{Toenail and Urine Collection and Analysis}

Toenail samples were collected from the study subjects and analyzed as described previously [23]. The nail samples were first cleaned by sonication in HPLC-grade water, then acetone was added to remove the organic contaminants from the nail surface. Nail samples were analyzed for arsenic concentration by instrumental neutron activation analysis (INAA) at the Nuclear Services Department, North Carolina State University, Raleigh, NC, USA [24]. The detection limit by INAA was $0.012 \mu \mathrm{g}$ of As ${ }^{\mathrm{III}} / \mathrm{g}$. Urine sample collection and analysis were the same as those described by [25]. Briefly, morning urine samples were collected from participants on three consecutive days and shipped on dry ice to the University of Alberta, Edmonton, AB, Canada for analysis. Inductively coupled mass spectrometry methods were used to measure urinary arsenic, with a detection limit of $0.5 \mu \mathrm{g}$ of $\mathrm{As}{ }^{\mathrm{III}} / \mathrm{L}$.

\subsection{Blood Collection, RNA Isolation, and cDNA Synthesis}

Blood samples were collected in PAXgene blood RNA tubes (Qiagen, Valencia, CA, USA) and then stored at $-40{ }^{\circ} \mathrm{C}$. The blood samples were transported to the U.S. A via air on blue ice and stored at $-80{ }^{\circ} \mathrm{C}$ until RNA isolation. Total RNA was isolated using a PAXgene blood RNA kit according to the manufacturer's instructions. RNA was further subjected to DNase I treatment using the Turbo DNA-free Kit following manufacturer's instructions (Applied Biosystems, Foster City, CA, USA). RNA quality was assessed by analysis with Agilent Bioanalyer 2100 Nono chip.

\section{5. cDNA Synthesis}

Total RNA was reverse-transcribed to cDNA by using High-Capacity cDNA Reverse Transcription Kits (Applied Biosystems, CA, USA). The reaction mix was consisted of $2.5 \mathrm{U} / \mu \mathrm{L}$ of reverse transcriptase, $1.0 \mathrm{U} / \mu \mathrm{L}$ of RNase inhibitor, $0.4-\mathrm{mM} \mathrm{dNTP}, 0.2-\mu \mathrm{M}$ random primers, and $2 \mu \mathrm{g}$ RNA in $50 \mu \mathrm{L}$ total volume. The reaction mixture was incubated at $25{ }^{\circ} \mathrm{C}$ for $10 \mathrm{~min}$ and then at $37{ }^{\circ} \mathrm{C}$ for $120 \mathrm{~min}$. Finally, the mixture was heated at $85^{\circ} \mathrm{C}$ for $5 \mathrm{~s}$. 


\subsection{TaqMan Low-Density Array}

To identify altered gene expression in blood cells, we used a TLDA to examine the expression of 46 human genes. The 46 genes we selected occurred in several functional groupings (Table 1) that represented proposed mode-of-actions of arsenic based on human epidemiology, as well as animal and in vitro studies. For the present study, the TaqMan low-density array card was configured in to eight identical 48 genes set (duplicate per assay). Each set of genes contained two endogenous control genes, $\beta$-actin and 18s RNA. The cDNA $(5 \mu \mathrm{L})$ was mixed with $45 \mu \mathrm{L}$ of $\mathrm{H}_{2} \mathrm{O}$ and $50 \mu \mathrm{L}$ of $2 \mathrm{X}$ TaqMan Universal PCR Mix (Applied Biosystems, Foster City, CA). Each sample (100 $\mu \mathrm{L})$ was loaded into a port of the micro-fluid card and run on an ABI 7900HT System (ABI, CA) for 2 min at $50{ }^{\circ} \mathrm{C}, 10 \mathrm{~min}$ at $95{ }^{\circ} \mathrm{C}$, followed by 40 cycles for $15 \mathrm{~s}$ at $97^{\circ} \mathrm{C}$ and 1 min at $60{ }^{\circ} \mathrm{C}$.

\subsection{In Vitro Studies}

The human cardiomyocyte cell line (AC16) was provided by one of us (M. Davidson) and were cultured in Dulbecco's Modified Eagle's/F12 medium supplemented with 12.5\% fetal bovine serum (Invitrogen, Carlsbad, CA, USA), penicillin (100 U/mL), and streptomycin $(100 \mu \mathrm{g} / \mathrm{mL})$ and maintained at $37{ }^{\circ} \mathrm{C}$ in $95 \%$ air and $5 \% \mathrm{CO}_{2}$. The MTT cell-proliferation assay kit (Roche, Indianapolis, IN, USA) was used to assess cell viability. Briefly, 1 X $10^{4}$ AC16 cells were seeded in 96-well plates in $0.2 \mathrm{~mL}$ of medium. After $24 \mathrm{~h}$ of incubation, sodium arsenite was added to the cultures at final concentrations of 0.1 to $5.0 \mu \mathrm{M}$, and cells were incubated for 3 days. Cell viability was measured at $560 \mathrm{~nm}$ and expressed as a percentage of controls. The assay was conducted in triplicate wells for each treatment, and a total of 3 experiments were conducted for all samples.

\subsection{Arsenite Treatment and RNA Isolation}

After incubating the seeded cells for $24 \mathrm{~h}$, the cells were treated with sodium arsenite (Sigma, St. Louis, MO, USA) at concentrations of 0 to $2.5 \mu \mathrm{M}$ for $72 \mathrm{~h}$. Total RNA was isolated from the control and the arsenite-treated cells using the RNeasy RNA Isolation Kit (Qiagen, CA, USA). cDNA synthesis and the TILDA were conducted as described above; each sample was tested in duplicate.

\subsection{Data Analysis}

The TLDA data were analyzed by SDS vers 2.2.2 software (ABI). Threshold cycle $(\mathrm{Ct})$ data for all target genes and control gene 18s RNA were used to calculate $\Delta \mathrm{Ct}$ values $[\Delta \mathrm{Ct}=\mathrm{Ct}$ (target gene) $\mathrm{Ct}$ (18s RNA)]. Then, $\Delta \Delta \mathrm{Ct}$ values were calculated by subtracting the calibrator (control) from the $\Delta \mathrm{Ct}$ values of each target. Multiple linear regression models were used to evaluate the relationship between gene expression $(\Delta \mathrm{Ct})$ and nail, water, and urine arsenic levels. Because arsenic measures were highly right-skewed, they were $\log _{10}$-transformed prior to analysis. The dependent variable was gene expression as measured by $\Delta \mathrm{Ct}$ value, and the independent variable of interest was the log-transformed arsenic measure. Log transformation did not improve the skew of $\Delta \mathrm{Ct}$ measures, which tended to be fairly symmetric.

Three types of models were constructed: an unadjusted model; a model that included variables to adjust for age and sex; and a model adjusting for age, body mass index, sex, alcohol use, pesticide 
exposure in the past five years, and education level. Because adjusting for factors other than age and sex did little to change the relationship between arsenic density and gene expression, results adjusting for age and sex were reported. Slope coefficients shown in Table 3 can be interpreted as the change in gene expression $(\Delta \mathrm{Ct})$ associated with a $1-\log _{10}$ increase in the water, urine, or nail arsenic levels. Non-linearity in the relationship between arsenic and gene expression was evaluated by fitting a two-degree fractional polynomial model and comparing it with a linear model using a deviance difference test [26]. Statistical analyses were conducted using Stata SE version 10.1 (Stata Corporation, College Station, TX, USA, 2008).

\section{Results}

\subsection{Study Subjects}

Demographic information and pesticide use related to the study subjects are shown in Table 2. All subjects were non-smokers. Most (79\%) of the 159 study subjects, including 48 males and 111 females, were farmers. The nail arsenic concentrations ranged from 0.24 to $63.14 \mu \mathrm{g} / \mathrm{g}$. Water arsenic concentrations ranged from non-detectable to $826 \mathrm{mg} / \mathrm{L}$. The average years of arsenic exposure for the study subjects was $13 \pm 6(\mathrm{SD})$ years.

Table 2. Selected characteristics of study population.

\begin{tabular}{lcc}
\hline Variables & Number of subjects & Percent \\
\hline Gender & 48 & \\
Male & 111 & 30.2 \\
Female & & 69.8 \\
Age & 49 & \\
$11-18$ & 93 & 30.8 \\
$19-49$ & 17 & 58.5 \\
$>50$ & & 10.7 \\
Occupation & 110 & \\
Farmer & 48 & 69.6 \\
Other & & 30.4 \\
Education & 24 & 15.2 \\
None & 50 & 31.6 \\
Elementary & 76 & 48.1 \\
Jr high school & 8 & 5.1 \\
High school & & \\
Meat frequency & 159 & 100 \\
Often & & \\
Vegetable frequency & 1 & 0.6 \\
Occasionally & 158 & 28.3 \\
Often & & 71.7 \\
Use of pesticides in past 5 years & 45 & \\
Yes & 114 & \\
No & & \\
\hline & & \\
\hline
\end{tabular}


Table 2. Cont.

\begin{tabular}{lcc}
\hline Variables & Number of subjects & Percent \\
\hline Alcohol use 2 x/week & 114 & \\
No & 7 & 95.6 \\
Yes & & 4.4 \\
Eat fish frequency & 1 & 0.6 \\
Never & 146 & 91.8 \\
Occasionally & 12 & 7.5 \\
Often & & \\
\hline
\end{tabular}

\subsection{Variability of Gene Expression Data from TLDA}

To assess the reproducibility of the TILDA, sixteen samples of cDNAs from human blood were run repeatedly. $\Delta \mathrm{Ct}$ (The $\mathrm{Ct}$ values normalized to loading control) for experiment 1 were plotted against $\triangle \mathrm{Ct}$ for repeated TLDA experiments. The data showed a small variation with high correlation coefficients (0.985 and 0.971) (Figures $1 \mathrm{~A}, \mathrm{~B})$. The data showed that the $\Delta \mathrm{Cts}$ were reproducible.

Figure 1. Viability of cardiomyocytes exposed to sodium arsenite. AC16 cells were seeded in a 96-well plate and exposed for three days to various concentrations of sodium arsenite. Cell viability was determined by the MTT assay. Data shown are mean \pm SD from three independent experiments.

A

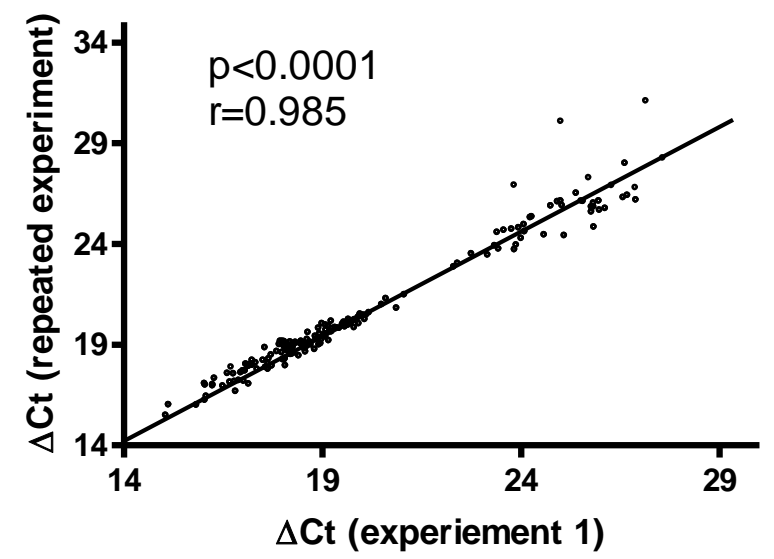

B

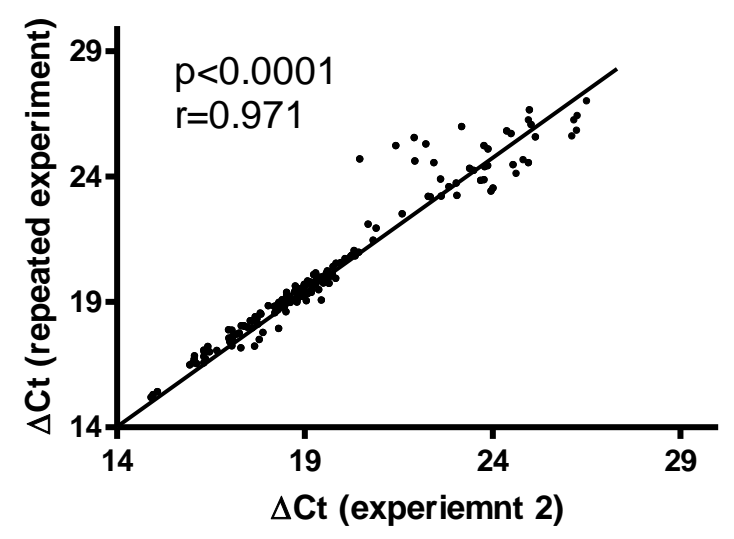




\subsection{Arsenic-Altered Gene Expression in the Blood}

The TLDA showed that the majority of selected genes were expressed in the blood, most of them with $\mathrm{Cts}<30$. However, hTERT and CANC1 were under the detectable limit $(\mathrm{Ct}>37)$ and, thus, were excluded from further analysis. A linear regression was employed to determine the significance of association of expression with water arsenic levels. The data from KCNA5 and TNF $\alpha$ expression showed a positive association with water arsenic exposure (Table 3). Furthermore, the expression level of KCNA5 was also associated with nail arsenic concentrations, whereas that of TNF- $\alpha$ was also associated with urine arsenic concentrations.

In addition to $K C N A 5$ and $T N F-\alpha$, the altered expressions of nine other genes were associated with urinary arsenic concentrations (Table 3). The associated molecular functions for these 11 gene products included stress response, inflammation, apoptosis, DNA methylation, DNA repair, and the NF- $\kappa \mathrm{B}$ signal transduction pathway. TNF- $\alpha$ is the prototypic pro-inflammatory cytokine and master regulator of cell apoptosis, inflammation, and tumorigenesis. TNF- $\alpha$ is an important constituent of the NF-kB signal pathway. There was no evidence of a significant $(p<0.05)$ non-linear relationship between water, nail, or urine arsenic levels and gene expression, and in all cases a 2-degree fractional polynomial model was not an improvement over a linear regression model.

Table 3. Association of gene expression with water, nail, or urine arsenic levels a

\begin{tabular}{|c|c|c|c|c|c|c|c|}
\hline \multirow[t]{2}{*}{ Gene } & \multirow[t]{2}{*}{ Function group } & \multicolumn{2}{|c|}{ Water arsenic } & \multicolumn{2}{|c|}{ Nail arsenic } & \multicolumn{2}{|c|}{ Urine arsenic } \\
\hline & & Slope & $p_{\text {value }}{ }^{b}$ & Slope & p value & Slope & p value \\
\hline KCNA5 & Ion channel & 0.343 & 0.031 & 0.547 & 0.043 & 0.189 & 0.078 \\
\hline$T N F-\alpha$ & Inflammation & 0.178 & 0.043 & & & 0.146 & 0.013 \\
\hline$P O L B$ & DNA repair & & & 0.306 & 0.049 & 0.135 & 0.028 \\
\hline$M A F$ & Nrf2 pathway & & & & & 0.137 & 0.038 \\
\hline$B C L 2$ & Apoptosis & & & & & 0.131 & 0.033 \\
\hline$B A X$ & Apoptosis & & & & & 0.117 & 0.038 \\
\hline DNMT1 & DNA methylation & & & & & 0.122 & 0.031 \\
\hline$H S P 1$ & Heat shock protein & & & & & 0.105 & 0.054 \\
\hline$J U N$ & Signal transduction & & & & & 0.149 & 0.023 \\
\hline NTHL1 & DNA repair & & & & & 0.132 & 0.034 \\
\hline$R A D 50$ & DNA repair & & & & & 0.113 & 0.050 \\
\hline
\end{tabular}

${ }^{\text {a }}$ Only those slopes and $p$-values with significant association with arsenic $(p<0.05)$ are shown;

${ }^{\mathrm{b}} \mathrm{N}=159, p$-values were age and sex adjusted.

\subsection{Cardiomyocytes Treated with Arsenite In Vitro}

Results from the MTT assay showed that the viability of AC16 cells after arsenic treatment decreased as arsenite concentrations increased (Figure 2). For the mRNA levels of 46 genes, three different patterns of response were observed. The expression of one group of genes was increased at low concentrations of arsenic $(0.5$ and $1 \mu \mathrm{M})$ but decreased at higher concentrations $(>2.5 \mu \mathrm{M}$, Figure 3A). These included the genes associated with heat shock proteins, inflammatory molecules, apoptosis, DNA repair, and the NFkB pathways (Figure 3A). A second group, including the genes $H M O X 1, N Q O 1$ and ESRl, showed increased expression relative to increased arsenic concentrations 
up to $5 \mu \mathrm{M}$ (Figure 3B). A third group showed down-regulated gene expression relative to arsenic concentration, and these included the ion channel genes CACNA1C, KCNE1, KCNQ1 and SCDA5; the DNA repair genes ERCC1 and NTHL1; and the cytokine gene IL6 (Figure 3C).

Figure 2. Correlation plot of mean $\Delta \mathrm{Ct}$ values from repeated TLDA experiments. Panels $\mathrm{A}$ and $\mathrm{B}$ show representative $\Delta \mathrm{Ct}$ values obtained from repeated experiment with two different samples. The $\Delta \mathrm{Ct}$ (The $\mathrm{Ct}$ values normalized to loading control) for experiment 1 was plotted against the $\Delta \mathrm{Ct}$ for repeated TILDA runs. Linear regression analysis was used to determined Pearson correlation coefficient (r) and $p$ values.

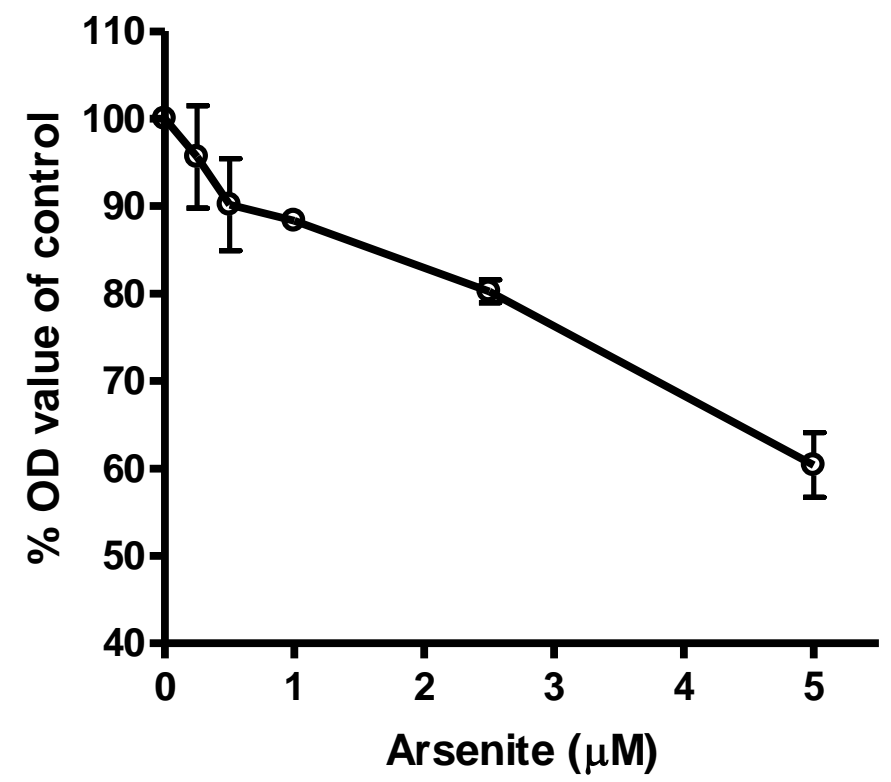

Values in Figure 3 are fold changes of expression in treated cells relative to control cells. The $\Delta \mathrm{Ct}$ values of untreated cells were designated as calibrators. The relative quantity (RQ) was calculated by the equation $\mathrm{RQ}=2^{-\Delta \Delta \mathrm{Ct}}$. (A) Up-regulated gene expression at low concentrations of arsenic but down-regulated expression at high concentrations $(2.5 \mu \mathrm{M})$. (B) Up-regulated gene expression relative to increasing concentrations of arsenic. (C) Down-regulated gene expression relative to increasing concentrations of arsenic.

\section{Discussion}

\subsection{Changes in Gene Expression in Blood Associated with Chronic Arsenic Exposure}

In this study, we investigated the molecular responses to arsenic exposure in humans and cultured cardiomyocytes using a novel TLDA in order to better understand the mode of action of arsenic. In blood, we found that alterations in expression of 11 genes, especially those associated with stress response, DNA repair, DNA methylation, the NF- $\mathrm{B}$ signaling pathway, and iron channels, were positively associated with arsenic exposure. Urinary arsenic concentrations were associated with altered expression of 10 genes, 8 of which were associated only with urinary arsenic levels. Expression of 3 genes was associated with binary combinations of the 3 exposure assessments (Table 3 ). Based on the TLDA we designed, urinary arsenic was the most robust measure of exposure. Considering all the 
exposure estimates, expression of $T N F-\alpha$ was associated with both water and urinary concentrations of arsenic, that of $P O L B$ was associated with nail and urinary levels, and that of KCNA5 was associated with water and nail levels (and was borderline significant with urinary arsenic). Because altered expression of these genes was associated with 2 of the 3 exposure assessments, we view that arsenic exposure clearly played a role in the altered expression of $K C N A 5, T N F-\alpha$, and POLB as assessed by the TLDA in this study.

Figure 3. Gene expression analysis of cardiomyocyte AC16 cells exposed to sodium arsenite for $72 \mathrm{~h}$ as determined by a TLDA.

A

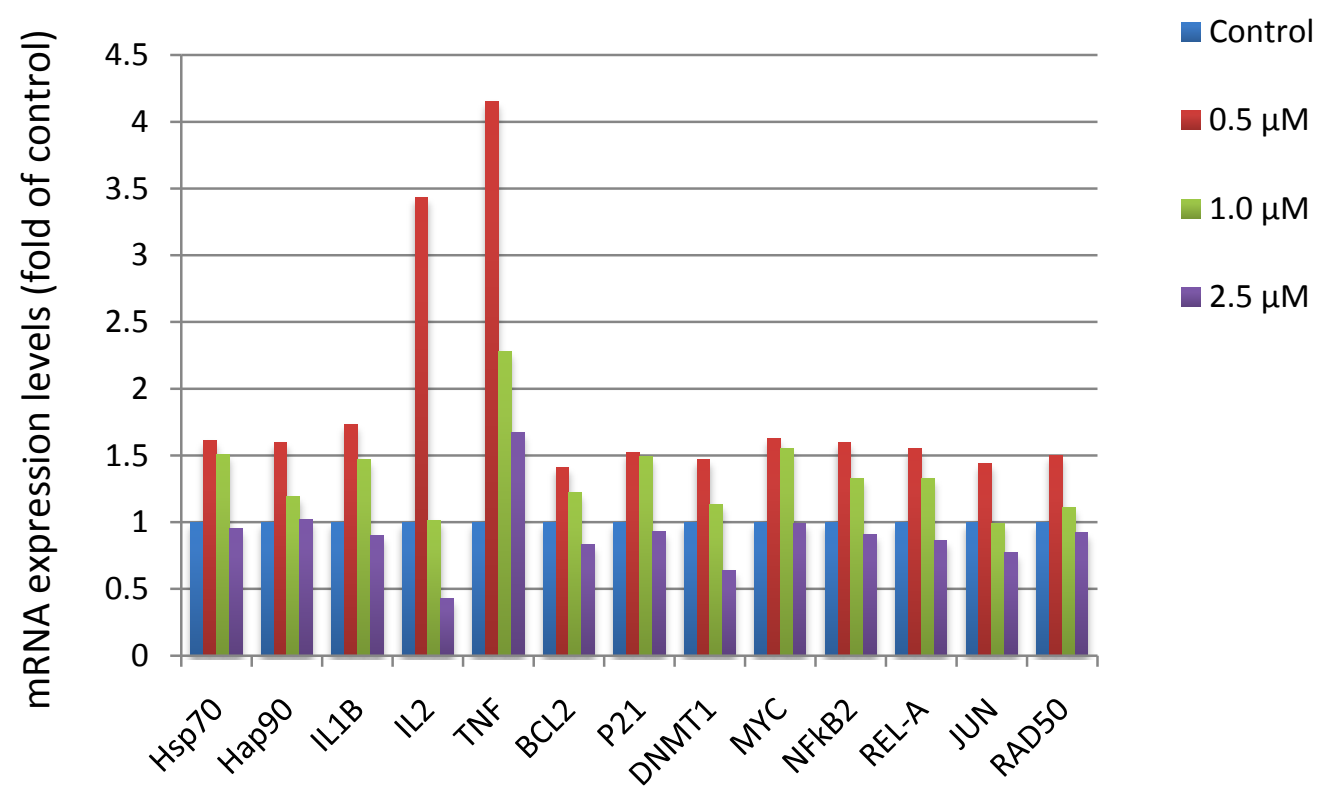

Arsenic-induced low dose response genes

B

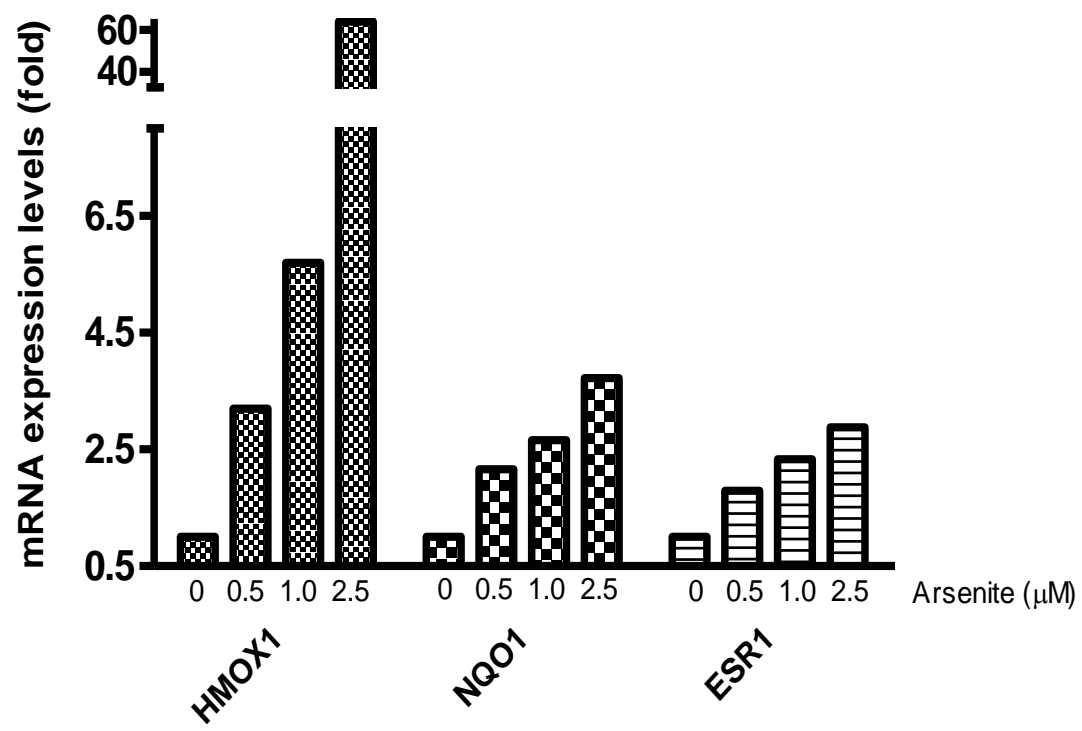


Figure 3. Cont.

\section{C}

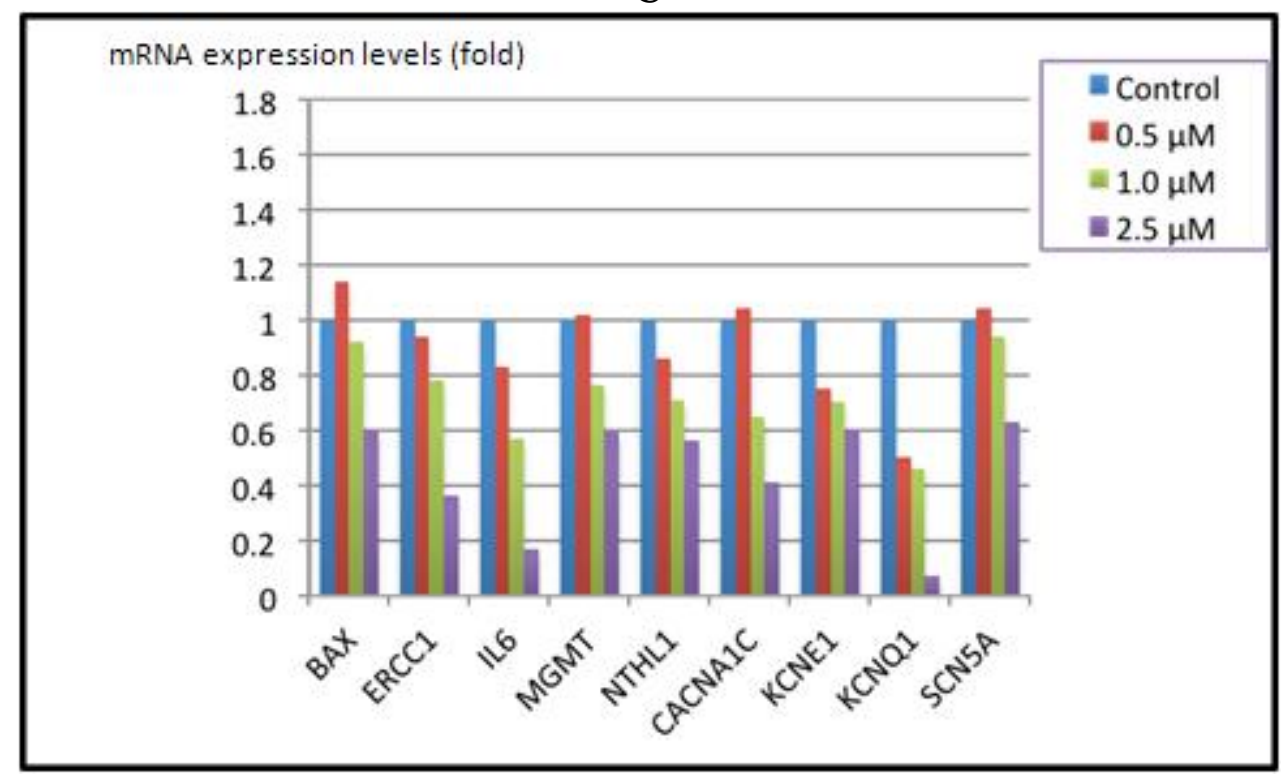

Our finding that altered gene expression was associated most frequently with urinary arsenic levels is interesting in light of the finding that urinary arsenic levels were a stronger predictor of skin lesions than arsenic levels in drinking water [27,28]. In addition, chromosomal aberrations have been shown to be associated with urinary arsenic [29]. Urinary arsenic receives input from external sources and tissue storage and likely reflects the body burden of arsenic. Consequently, altered gene expression associated with urinary arsenic may reflect current arsenic exposure levels.

Expression of KCNA5 influences various cell functions, such as cell migration, proliferation and apoptosis. Over-expression of human KCNA5 in pulmonary artery smooth muscle cells induced membrane hyperpolarization and increased cell apoptosis [30]. Down-regulation of KCNA5 expression by an antisense oligonucleotide resulted in membrane depolarization [31]. KCNA5 expression occurs in response to oxidative stress mediated by the Sp1 transcription factor [32].

TNF- $\alpha$ is a cytokine involved in cell proliferation, differentiation, and apoptosis. Induction of TNF- $\alpha$ by arsenic exposure has been observed consistently both in vitro and in vivo [33,34]. Over-expression of $T N F-\alpha$ and $G M-C S F$ has been associated with neoplastic transformation in the skin. $T G F-\alpha$ transgenic mice exhibited keratinocyte hyper-proliferation and tumors in the epithelium [35]. Our PCR array profiling showed that $T N F-\alpha$ expression was positively associated with chronic arsenic exposure, indicating that this inflammation cytokine is involved in arsenic toxicity and possibly carcinogenesis. Some TNFs may induce both apoptotic and anti-apoptotic pathways, the increased expression of TNF- $\alpha$, along with BCL2 and BAX, strongly indicate the activation of the anti-apoptotic/NF- $\mathrm{B} / \mathrm{BCL} 2$ pathway in the subjects exposed to environmental arsenic.

Expression of $J U N$ and $M A F$ was positively associated with urinary arsenic levels in this study. The coordinated induction of these two genes suggests that the Nrf2 pathway plays a crucial role in the cellular defense against arsenic-induced oxidative stress, which has been reported to be involved in the toxicity induced by low-dose arsenic exposure [36]. The Nrf2 pathway plays an important role by mediating an antioxidant response against the adverse effects of excess ROS production generated by 
arsenic metabolites [37]. The transcription factor $\mathrm{Nrf} 2$ is a central regulator in the activation of many genes related to antioxidant response, such as glutathione $\mathrm{S}$-transferase $(G S T), N A D(P) H$, quinine reductases (NQO1), heat shock protein, and heme oxygenase $1(\mathrm{HO}-1)$. Although we did not have GGT1 or NFKBIE on our array, their expression levels in lymphoblasts may be biomarkers of susceptibility arsenic toxicity [38].

The small Maf basic leucine zipper protein has emerged as a crucial regulator of mammalian gene expression. During oxidative stress, Nrf2 heterodimerizes with small Maf and binds antioxidant response element (ARE) sequences, thereby transcriptionally activating ARE [37]. The activator protein (AP-1) transcription factor is a protein complex consisting c-Jun and c-Fos, which are involved in the regulation of many different kind of cellular processes, including proliferation and survival, differentiation, and transformation. Consistent with this is the finding that expression of $c$-Jun and c-Fos was up-regulated in human GM847 fibroblast cells exposed to arsenic [39]. Our finding of up-regulated expression of $c$-Jun and Maf in humans exposed chronically to arsenic suggests that arsenic may alter $A P-1$ and $N F-\kappa b$ activity. The NFKB signaling pathway is involved in the immune response, inflammation, and apoptosis, and the inflammation/NF- $\kappa \mathrm{B}$ signaling pathway was reported to be activated in infants born to arsenic-exposed mothers [15]. Our data and that of others $[15,40]$ suggest that NFאB activation induced by arsenic exposure may play an important role in arsenic toxicity in humans.

Arsenic exposure is associated with a variety of diseases, including cancer, cardiovascular disease, and diabetes $[1,8,41]$. The mechanisms underlying the carcinogenicity of arsenic are varied; however, oxidative stress is a likely mode of action for arsenic [1,3]. Arsenic metabolites generate ROS, resulting in damage to DNA and other macromolecules. For example, ROS-generating metabolites of arsenic can induce DNA breaks, resulting in chromosomal mutations [42]. The association of arsenic exposure with increased gene expression of nucleotide excision repair, DNA methylation, and oxidative DNA repair pathways observed in this study is consistent with this mechanism of arsenic carcinogenicity. As discussed below, oxidative stress may also play a role in the cardiovascular diseases associated with arsenic exposure, further supporting a role for the genes identified here in arsenic-associated disease.

\subsection{Changes in Gene Expression in Arsenic-Exposed Cardiomyocytes}

Several reviews have concluded that arsenic exposure is associated with cardiovascular disease $[8,41,43]$. The specific diseases include carotid atherosclerosis, reduced microcirculation, prolonged QT interval and increased QT dispersion, hypertension, coronary artery disease, and cerebral infarction. Epidemiology studies support the view that chronic arsenic exposure is an independent risk factor for cardiovascular disease. Our previous work has demonstrated a clear relationship between chronic arsenic exposure and QT interval prolongation [5].

The mechanistic basis for this collection of arsenic-associated health effects appears to involve a role for oxidative stress and activated immune response pathways, indicating a pro-hyperinflammatory condition [8]. In arsenic-exposed mice, the arterial wall is inflamed, and liver sinusoidal endothelium differentiates into a continuous endothelium that limits nutrient exchange and waste elimination. Thus, 
current models focus on altered signaling by arsenic, resulting in inflammation of liver and heart arteries [8].

To our knowledge, our study is the first to expose heart cells (cardiomyocytes) to arsenic in vitro. We found that 25 of the 46 genes assessed by our TLDA exhibited altered expression after exposure of cardiomyocytes to arsenic (Figure 3). Most interesting was that these affected genes fell into three categories: (1) those whose expression was up-regulated at low concentrations of arsenic but down-regulated at high concentrations of arsenic (Figure 3A), those whose expression was up-regulated with increasing concentrations of arsenic (Figure 3B), and those whose expression were down-regulated with increasing concentrations of arsenic (Figure 3C).

Various studies have noted consistently that, for some genes, arsenic induces expression at low doses but reduces expression at high doses in vitro and in vivo. In human keratinocytes, sodium arsenite induced apurinic/apyrimidinic endonuclease, DNA polymerase $\beta$, DNA ligase, and telomerase up to $1 \mu \mathrm{M}$, but down-regulated these genes at concentration $>1 \mu \mathrm{M}[39,44,45]$. The sub-micromolar concentrations of sodium arsenite used in our study are similar to the levels of arsenic found in the blood of subjects exposed chronically to arsenic in Inner Mongolia [46]. These results suggest that low doses of arsenic trigger an adaptive response that alleviates the adverse effects of arsenic cytotoxicity and oxidative stress. Some of this response could protect against cancer by elevated DNA repair capacity. Other responses, such as increased cell proliferation, or inhibited apoptosis, may be cytoprotective, but could also be procarcinogenic by allowing mutant cells to survive.

Transcriptional regulation plays a key role in the regulation of potassium channel genes involved in cardiac muscle function and accounts for some of the variation of the elecrtro-physiological phenotype of myocytes [47]. Therefore, expression of KCNA5 may have been altered by arsenic in the cardiomyocytes, but because of the low levels of this mRNA in our cells, we could not confirm such a change. However, we observed transcriptional changes for several iron-channel genes, including $K C N E 1, K C N H 2$, and $C A D A 1 C$ in cardiomyocytes treated with arsenite. Alterations in such genes could play a role in the cardiac arrhythmias associated with arsenic exposure $[5,48]$.

As noted earlier, epidemiological studies have identified arsenic exposure as a causative agent for diabetes $[5,41,43]$. Although we did not design our TLDA to assess genes potentially involved in arsenic-associated diabetes, recent studies [49,50] suggest that the arsenic-associated decrease in insulin secretion found in rodent models may be partially responsible for the altered cell division and proliferation associated with arsenic exposure. In vitro studies found that free $\mathrm{Ca}^{(2+)}$ oscillations needed for glucose-stimulated insulin secretion were abated in the presence of subchronic, low arsenite concentrations [50]. Thus, it is interesting that we found that arsenic reduced expression of a variety of ion channel genes, including the calcium channel, voltage-dependent, $\mathrm{L}$ type alpha $1 \mathrm{C}$ subunit gene CACNAIC in cardiomyocytes (Figure 3C). Although it is difficult to make firm conclusions and direct comparisons of gene expression in cardiomyocytes and blood due to the nature of the study design and differences in absorption and metabolismwe found that five genes showed altered expression both in blood and in the treated cardiomyocytes: BAX, DNMT1, JUN, NTHL1, and RAD50. 


\section{Conclusions}

In conclusion, this study shows that the TLDA is a sensitive and reproducible technique for quantifying expression of multiple genes. Our finding in the blood of arsenic-exposed subjects of the simultaneous increase in gene expression involved in antioxidant response, inflammatory response, DNA repair, apoptosis, DNA methylation, and iron channels, suggests an integrative mode of action of arsenic in humans. Oxidative stress, inflammatory response, and altered ion-channel function may underlay aspects of the cancer, cardiovascular disease, and diabetes associated with chronic arsenic exposure. A recent study has also identified the importance of epigenetic changes in people with arsenicosis [51]. Further studies involving specific cell types are needed to identify the complete set of pathways affected by arsenic that result in the array of seemingly unrelated diseases.

\section{Acknowledgements}

We thank the staff members of the Inner Mongolia Center for Endemic Disease Control and Research and Ba Men Anti-epidemic Station who participated in this study. The research described here has been reviewed by the National Health and Environmental Effects Research Laboratory, U.S. Environmental Protection Agency, and approved for publication. Approval does not signify that the contents necessarily reflect the views and policies of the agency, nor does mention of trade names or commercial products constitute endorsement or recommendation for use.

\section{References}

1. International Agency for Research on Cancer (IARC). IARC Monographs on the Evaluation of Carcinogenic Risks to Humans. Some Drinking-Water Disinfectants and Contaminants, Including Arsenic; IARC: Lyon, France, 2004; Volume 84.

2. Tapio, S.; Grosche, B. Arsenic in the aetiology of cancer. Mutat. Res. 2006, 612, 215-246.

3. Straif, K.; Benbrahim-Tallaa, L.; Baan, R.; Grosse, Y.; Secretan, B.; El Ghissassi, F.; Bouvard, V.; Guha, N.; Freeman, C.; Galichet, L.; et al. A review of human carcinogens-Part C: Metals, arsenic, dusts, and fibres. Lancet Oncol. 2009, 10, 453-454.

4. Rossman, T.G.; Uddin, A.N.; Burns, F.J. Evidence that arsenite acts as a cocarcinogen in skin cancer. Toxicol. Appl. Pharmacol. 2004, 198, 394-404.

5. Mumford, J.L.; Wu, K.; Xia, Y.; Kwok, R.; Yang, Z.; Foster, J.; Sanders, W.E. Chronic arsenic exposure and cardiac repolarization abnormalities with QT interval prolongation in a population-based study. Environ. Health Perspect. 2007, 115, 690-694.

6. Westervelt, P.; Brown, R.A.; Adkins, D.R.; Khoury, H.; Curtin, P.; Hurd, D.; Luger, S.M.; Ma, M.K.; Ley, T.J.; DiPersio, J.F. Sudden death among patients with acute promyelocytic leukemia treated with arsenic trioxide. Blood 2001, 98, 266-271.

7. Sanz, M.A.; Grimwade, D.; Tallman, M.S.; Lowenberg, B.; Fenaux, P.; Estey, E.H.; Naoe, T.; Lengfelder, E.; Büchner, T.; Dőhner, H.; Burnett, A.K.; Lo-Coco, F. Management of acute promyelocytic leukemia: recommendations from an expert panel on behalf of the European LeukemiaNet. Blood 2009, 113, 1875-1891. 
8. States, J.C.; Srivastava, S.; Chen, Y.; Barchowsky, A. Arsenic and cardiovascular disease. Toxicol. Sci. 2009, 107, 312-323.

9. Wade, T.J.; Xia, Y.; Wu, K.; Li, Y.; Ning, Z.; Le, X.C.; Lu, X.; Feng, Y.; He, X.; Mumford, J.L. Increased mortality associated with well-water arsenic exposure in Inner Mongolia, China. Int. J. Environ. Res. Public Health 2009, 6, 1107-1123.

10. Wang, C.H.; Chen, C.L.; Hsiao, C.K.; Chiang, F.T.; Hsu, L.I.; Chiou, H.Y.; Hsueh, Y.M.; $\mathrm{Wu}$, M.M.; Chen, C.J. Increased risk of QT prolongation associated with atherosclerotic diseases in arseniasis-endemic area in southwestern coast of Taiwan. Toxicol. Appl. Pharmacol. 2009, 239, 320-324.

11. Mordukhovich, I.; Wright, R.O.; Amarasiriwardena, C.; Baja, E.; Baccarelli, A.; Suh, H.; Sparrow, D.; Vokonas, P.; Schwartz, J. Association between low-level environmental arsenic exposure and QT interval duration in a general population study. Am. J. Epidemiol. 2009, 170, 739-746.

12. Liu, J.; Kadiiska, M.B.; Liu, Y.; Lu, T.; Qu, W.; Waalkes, M.P. Stress-related gene expression in mice treated with inorganic arsenicals. Toxicol. Sci. 2001, 61, 314-320.

13. Rea, M.A.; Gregg, J.P.; Qin, Q.; Phillips, M.A.; Rice, R.H. Global alteration of gene expression in human keratinocytes by inorganic arsenic. Carcinogenesis 2003, 24, 747-756.

14. Argos, M.; Kibriya, M.G.; Parvez, F.; Jasmine, F.; Rakibuz-Zaman, M.; Ahsan, H. Gene expression profiles in peripheral lymphocytes by arsenic exposure and skin lesion status in a Bangladeshi population. Cancer Epidemiol. Biomarkers Prev. 2006, 15, 1367-1375.

15. Fry, R.C.; Navasumrit, P.; Valiathan, C.; Svensson, J.P.; Hogan, B.J.; Luo, M.; Bhattacharya, S.; Kandjanapa, K.; Soontararuks, S.; Nookabkaew, S.; et al. Activation of inflammation/NF-kB signaling in infants born to arsenic-exposed mothers. PLoS Genet. 2007, 3, e207.

16. Ghosh, P.; Banerjee, M.; Giri, A.K.; Ray, K. Toxcogenomics of arsenic: Classical ideas and recent advances. Mutat. Res. 2008, 659, 293-301.

17. Abruzzo, L.V.; Lee, K.Y.; Fuller, A.; Silverman, A.; Keating, M.J.; Medeiros, L.J.; Coombes, K.R. Validation of oligonucleotide microarray data using microfluidic low-density arrays: A new statistical method to normalize real-time RT-PCR data. Biotechniques 2005, 38, 785-792.

18. Goulter, A.B.; Harmer, D.W.; Clark, K.LO. Evaluation of low density array technology for quantitative parallel measurement of multiple genes in human tissue. BMC Genomics 2006, 7, 34.

19. Ma, H.Z.; Xia, Y.J.; Wu, K.G.; Sun, T.Z.; Mumford, J.L. Human exposure to arsenic and health effects in Bayingnormen, Inner Mongolia. In Arsenic Exposure and Health Effects; Abernathy, W.R., Calderon, C.O., Chappell, R., Eds.; Elsevier: Amsterdam, The Netherlands, 1999; pp. 127-131.

20. Mo, J.; Xia, Y.; Wade, T.J.; Schmitt, M.; Le, X.C.; Dang, R.; Mumford, J.L. Chronic arsenic exposure and oxidative stress: OGG1 expression and arsenic exposure, nail selenium, and skin hyperkeratosis in Inner Mongolia. Environ. Health Perspect. 2006, 114, 835-841.

21. World Medical Association. Declaration of Helsinki, 1989. Available online: http://www.wma.net/e/policy/pdf/17c.pdf (accessed on 23 March 2011).

22. Gong, Z.; Lu, X.; Watt, C.; Wen, B.; He, B.; Mumford, J.; Ning, Z.; Xia, Y.; Le, X.C. Speciation analysis of arsenic in groundwater from Inner Mongolia with an emphasis on acid-leachable particulate arsenic. Anal. Chim. Acta 2006, 555, 181-187. 
23. Schmitt, M.T.; Schreinemachers, D.; Wu, K.; Ning, Z.; Zhao, B.; Le, X.C.; Mumford, J.L. Human nails as a biomarker of arsenic exposure from well water in Inner Mongolia: Comparing atomic fluorescence spectrometry and neutron activation analysis. Biomarkers 2005, 10, 95-104.

24. Heydorn, K. Neutron Activation Analysis for Clinical Trace Element Research; CRC Press: Boca Raton, FL, USA, 1984; Volumes 1 and 2.

25. Otto, D.; Xia, Y.; Li, Y.; Wu, K.; He, L.; Telech, J.; Hundell, H.; Prah, J.; Mumford, J.; Wade, T. Neurosensory effects of chronic human exposure to arsenic associated with body burden and environmental measures. Hum. Exp. Toxicol. 2007, 26, 169-177.

26. Royston, P.; Ambler, G.; Sauerbrei, W. The use of fractional polynomials to model continuous risk variables in epidemiology. Int. J. Epidemiol. 1999, 28, 964-974.

27. Watanabe, C.; Inaoka, T.; Kadono, T.; Nagano, M.; Nakamura, S.; Ushijima, K.; Murayama, N.; Miyazaki, K.; Ohtsuka, R. Males in rural Bangladeshi communities are more susceptible to chronic arsenic poisoning than females: Analyses based on urinary arsenic. Environ. Health Perspect. 2001, 109, 1265-1270.

28. Ahsan, H.; Perrin, M.; Rahman, A.; Parvez, F.; Stute, M.; Zheng, Y.; Milton, A.H.; Brandt-Rauf, P.; van Geen, A.; Graziano, J. Associations between drinking water and urinary arsenic levels and skin lesions in Bangladesh. J. Occup. Environ. Med. 2000, 42, 1195-1201.

29. Maki-Paakkanen, J.; Kurttio, P.; Paldy, A.; Pekkanen, J. Association between the clastogenic effect in peripheral lymphocytes and human exposure to arsenic through drinking water. Environ. Mol. Mutagen. 1998, 32, 301-313.

30. Bevnova, E.E.; Platoshyn, O.; Zhang, S.; Yuan, J.X. Overexpression of human KCNA5 increases IK V and enhances apoptosis. Am. J. Physiol. Cell Physiol. 2004, 287, C715-C722.

31. Nattel, S.; Bourne, G.; Talajic, M. Insights into mechanisms of antiarrythmic drug action from experimental models of atrial fibrillation. J. Cardiovasc. Electrophysiol. 1997, 8, 469-480.

32. Fountain, S.J.; Cheong, A.; Li, J.; Dondas, N.Y.; Zeng, F.; Wood, I.C.; Beech, D.J. K9v1.5 potassium channel gene regulation by $\mathrm{Sp} 1$ transcription factor and oxidative stress. Am. J. Physiol. Heart Circ. Physiol. 2007, 293, H2719-H2725.

33. Germolec, D.R.; Spalding, J.; Boorman, G.A.; Wilmer, J.L.; Yoshida, T.; Simeonova, P.P.; Bruccoleri, A.; Kayama, F.; Gaido, K.; Tennant, R.; et al. Arsenic can mediate skin neoplasia by chronic stimulation of keratinocyte-derived growth factors. Mutat. Res. 1997, 386, 209-218.

34. Yih, L.H.; Peck, K.; Lee, T.C. Changes in gene expression profiles of human fibroblasts in response to sodium arsenite treatment. Carcinogenesis 2002, 23, 867-876.

35. Simeonova, P.P.; Luster, M.I. Mechanisms of arsenic carcinogenicity: Genetic or epigenetic mechanisms? J. Environ. Pathol. Toxicol. Oncol. 2000, 19, 281-286.

36. Schoen, A.; Beck, B.; Sharma, R.; Dube, E. Arsenic toxicity at low doses: Epidemiological and mode of action considerations. Toxicol. Appl. Pharmacol. 2004, 198, 253-267.

37. Itoh, K.; Chiba, T.; Takahashi, S.; Ishii, T.; Igarashi, K.; Katoh, Y.; Oyake, T.; Hayashi, N.; Satoh, K.; Hatayama, I.; et al. An Nrf2/small Maf heterodimer mediates the induction of phase II detoxifying enzyme genes through antioxidant response elements. Biochem. Biophys. Res. Commun. 1997, 236, 313-322. 
38. Komissarova, E.V.; Li, P.; Uddin, A.N.; Chen, X.; Nadas, A.; Rossman, T.G. Gene expression levels in normal human lymphoblasts with variable sensitivities to arsenite: Identification of GGT1 and NFKBIE expression levels as possible biomarkers of susceptibility. Toxicol. Appl. Pharmacol. 2008, 226, 199-205.

39. Hu, Y.; Jin, X.; Snow, E.T. Effect of arsenic on transcription factor AP-1 and NF-kappaB DNA binding activity and related gene expression. Toxicol. Lett. 2002, 133, 33-45.

40. Liu, Q.; Zhang, H.; Smeester, L.; Zou, F.; Kesic, M.; Jaspers, I.; Pi, J.; Fry, R.C. The NRF2-mediated oxidative stress response pathway is associated with tumor cell resistance to arsenic trioxide across the NCI-60 panel. BMC Med. Genomics 2010, 3, 37.

41. Navas-Acien, A.; Sharrett, A.R.; Silbergeld, E.K.; Schwartz, B.S.; Nachman, K.E.; Burke, T.A.; Guallar, E. Arsenic exposure and cardiovascular disease: A systematic review of the epidemiologic evidence. Am. J. Epidemiol. 2005, 162, 1037-1049.

42. Kligerman, A.D.; Doerr, C.L.; Tennant, A.H.; Harrington-Brock, K.; Allen, J.W.; Winkfield, E.; Poorman-Allen, P.; Kundu, B.; Funasaka, K.; Roop, B.C.; Mass, M.J.; DeMarini, D.M. Methylated trivalent arsenicals as candidate ultimate genotoxic forms of arsenic: induction of chromosomal mutations but not gene mutations. Environ. Mol. Mutagen. 2003, 42, 192-205.

43. Wang, C.H.; Hsiao, C.K.; Chen, C.L.; Hsu, L.I.; Chiou, H.Y.; Chen, S.Y.; Hsueh, Y.M.; $\mathrm{Wu}, \mathrm{M} . \mathrm{M}$; Chen, C.J. A review of the epidemiologic literature on the role of environmental arsenic exposure and cardiovascular diseases. Toxicol. Appl. Pharmacol. 2007, 222, 315-326.

44. Sykora, P.; Snow, E.T. Modulation of DNA polymerase beta-dependent base excision repair in cultured human cells after low dose exposure to arsenite. Toxicol. Appl. Pharmacol. 2008, 228, 385-394.

45. Zhang, T.C.; Schmitt, M.T.; Mumford, J.L. Effects of arsenic on telomerase and telomeres in relation to cell proliferation and apoptosis in human keratinocytes and leukemia cells in vitro. Carcinogenesis 2003, 24, 1811-1817.

46. Pi, J.; Yamauchi, H.; Kumagai, Y.; Sun, G.; Yoshida, T.; Aikawa, H.; Hopenhayn-Rich, C.; Shimojo, N. Evidence for induction of oxidative stress caused by chronic exposure of Chinese residents to arsenic contained in drinking water. Environ. Health Perspect. 2002, 110, 331-336.

47. Dixon, J.E.; McKinnon, D. Quantitative analysis of potassium channel mRNA expression in atrial and ventricular muscle of rats. Circ. Res. 1994, 75, 252-260.

48. Wan, X.; Dennis, A.T.; Obejero-Paz, C.; Overholt, J.L.; Heredia-Moya, J.; Kirk, K.L.; Ficker, E. Oxidative inactivation of the lipid phosphatase phosphatase and tensin homolog on chromosome ten (PTEN) as a novel mechanism of acquired long QT syndrome. J. Biol. Chem. 2011, 286, 2843-2852.

49. Diaz-Villaseñor, A.; Burns, A.L.; Hiriart, M.; Cebrián, M.E.; Ostrosky-Wegman, P. Arsenic-induced alteration in the expression of genes related to type 2 diabetes mellitus. Toxicol. Appl. Pharmacol. 2007, 225, 123-133.

50. Diaz-Villaseñor, A.; Hiriart, M.; Cebrián, M.E.; Zacarías-Castillo, R.; Ostrosky-Wegman, P. The activity of calpains in lymphocytes is glucose-dependent and is decreased in diabetic patients. Blood Cells Mol. Dis. 2008, 40, 414-419. 
51. Smeester, L.; Rager, J.E.; Bailey, K.A.; Guan, X.; Smith, N.; García-Vargas, G.; Del Razo, L.M.; Drobná, Z.; Kelkar, H.; Stýblo, M.; Fry, R.C. Epigenetic changes in individuals with arsenicosis. Chem. Res. Toxicol. 2011, 24, 165-167.

(C) 2011 by the authors; licensee MDPI, Basel, Switzerland. This article is an open access article distributed under the terms and conditions of the Creative Commons Attribution license (http://creativecommons.org/licenses/by/3.0/). 